\title{
Brain inflammation induced by severe asphyxia in newborn pigs and the impact of alternative resuscitation strategies on the newborn central nervous system
}

\author{
Ingrid Dannevig ${ }^{1-4}$, Anne Lee Solevåg ${ }^{1-4}$, Tonje Sonerud ${ }^{1,2,5}$, Ola Didrik Saugstad ${ }^{3,4}$ and Britt Nakstad ${ }^{1,2}$
}

BACKGROUND: We compared the current guidelines for neonatal resuscitation with alternative measures and aimed to find out whether this modulated brain inflammation.

METHODS: Progressive asphyxia was induced in 94 newborn pigs until asystole. With the reference being resuscitation guidelines, 30 s of initial positive-pressure ventilation before compression $(C)$ and ventilation $(\mathrm{V})(\mathrm{C}: \mathrm{V} ; 3: 1)$ in $21 \%$ oxygen, pigs were randomized to (i) ventilation for 30,60, or 90 s before chest compressions; (ii) C:V ratios of 3:1, 9:3, or 15:2; or (iii) $21 \%$ or $100 \%$ oxygen. Concentrations of inflammatory markers in the cerebrospinal fluid (CSF) and gene expression in the hippocampus and frontal cortex were measured for different interventions.

RESULTS: In CSF, S100 was higher with 90 s than with 30 or 60 $s$ of initial positive-pressure ventilation, whereas concentrations of interleukin-6 (IL-6) and tumor necrosis factor-a (TNF-a) were higher with 30 than with 60 s. Matrix metalloproteinase-2 (MMP-2) and intracellular adhesion molecule 1 (ICAM-1) were higher with 30 than with $60 \mathrm{~s}$. No other comparison between ratios and oxygen concentrations used yielded significant results.

CONCLUSION: With respect to signs of brain inflammation, newly born pigs at asystole should be ventilated for longer than $30 \mathrm{~s}$ before chest compressions start. C: $V$ ratios of $9: 3$ and 15:2 as compared with 3:1, or air instead of pure oxygen, did not modulate inflammatory markers.

$\mathbf{T}$ he usual focus in neonatal resuscitation has been to restore cardiac and pulmonary function, but attention to brain protection has been increasing. Several studies suggest that it is possible to modify, if not reverse, the cerebral dysfunction and injury caused by inadequate oxygen delivery $(1,2)$. Acute asphyxia in term infants damages deep gray matter of the brain involving the thalamus, basal ganglia, and brainstem, often with sparing of the cerebral cortex (3). The resuscitation methods applied should be as gentle as possible to obtain the best short- and long-term outcomes.

After birth, if breathing efforts are absent or inadequate, lung aeration is the priority. Most infants needing resuscitation at birth will respond with a rapid increase in heart rate (HR) within $30 \mathrm{~s}$ of lung inflation. Today's guidelines recommend chest compressions with a ratio of three compressions to one ventilation $(3: 1)$ if the HR is $<60$ beats per minute despite adequate ventilation, aiming to achieve $\sim 120$ events per minute using air rather than $100 \%$ oxygen in term babies $(4,5)$. Performing chest compressions is an infrequent intervention during delivery room resuscitation and is estimated to occur in $\sim 1$ in 1,000 term deliveries but more often in preterm infants (6).

Extreme asphyxia with hypoxia, hyperoxia during resuscitation, and repetitive traumatic chest compressions are likely to contribute to the overall brain injury. Alternatives to today's ventilation and chest compression guidelines may be easier to perform and teach and should be considered if the brain inflammatory response is of similar intensity. We chose to study a spectrum of inflammation markers in cerebrospinal fluid (CSF) and brain tissue by quantification of cytokines, interleukin-6 (IL-6) (7-9) and tumor necrosis factor- $\alpha$ (TNF- $\alpha$ ) (10) and S100 $(11,12)$ in CSF, and gene expression of matrix metalloproteinases (MMPs) $(13,14)$, intercellular adhesion molecule 1 (ICAM-1) (15-17), the apoptosis-related cysteine peptidase caspase 3 (14), and cytokines IL- 6 and TNF- $\alpha$ in the hippocampus and frontal cortex tissue. On the basis of our previous papers on return of spontaneous circulation (ROSC) (18-21), we aimed to find out if initial ventilation periods longer than $30 \mathrm{~s}$, compression-to-ventilation $(\mathrm{C}: \mathrm{V})$ ratios other than the 3:1, or air instead of pure oxygen may induce less brain injury and inflammation in extremely sick pigs. Here, we question whether these alternative strategies induce less brain injury judged through responses in CSF cytokines and gene expression of inflammatory response genes.

\section{RESULTS}

Variations in Ventilation Time From Cardiac Arrest to Onset of Chest Compressions

All pigs were resuscitated with C:V ratio 3:1 and 21\% oxygen. Baseline characteristics are provided in Table 1. Clinical data during the hypoxia and resuscitation periods were not different between groups $1-3$, except for time to ROSC $(P<0.001)$, lower mean arterial pressure, and higher $\mathrm{PaCO}_{2}$ in group 3 as compared with group 1 immediately after ROSC (20) (both $P=0.007$ ). 


\section{Articles | Danneviget al.}

CSF

The S100 concentration was elevated in group 3 (90 s) (123.7 $\mu \mathrm{g} / \mathrm{l}$ (41.00-329.9), median (interquartile range)) as compared with group 1 (30 s) $(27.08 \mu \mathrm{g} / \mathrm{l}(24.11-62.36)), P=0.01$, whereas pigs in group 1 and group $2(60 \mathrm{~s})(31.29 \mu \mathrm{g} / \mathrm{l}(17.40-49.09))$ produced similar levels $(P=0.88)$. IL-6 levels were higher in group $1(80.81 \mathrm{pg} / \mathrm{ml},(26.82-359.6))$ than in group $2(20.11 \mathrm{pg} / \mathrm{ml}$ $(14.49-37.67)), P=0.02$, whereas group $3(58.70 \mathrm{pg} / \mathrm{ml},(20.21-$ $138.87))$ produced IL-6 levels similar to those in group $1(P=$ $0.35)$. CSF levels of TNF- $\alpha$ were higher in group $1(75.09 \mathrm{pg} / \mathrm{ml}$ (48.11-103.4)) than in group $2(26.56 \mathrm{pg} / \mathrm{ml}(15.73-53.49))$ and group $3(58.7 \mathrm{pg} / \mathrm{ml}(20.2-98.9)), P=0.01$ and $P=0.33$, respectively. Results are illustrated in Figure 1.

\section{Hippocampus and Frontal Cortex}

Gene expression in the hippocampus tissue of MMP-2 and ICAM-1 was higher in group 1 ventilated for $30 \mathrm{~s}$ as compared with group 2 (60 s), both $P=0.02$. The gene expression of IL-6, TNF- $\alpha$, caspase 3, and MMP-9 did not differ between groups. In the frontal cortex, we found no differences between the groups 1-3. All data and $P$ values are presented in Table 2 .

\section{Variations in Ratios of Chest C:V}

All pigs were resuscitated with ventilation for $30 \mathrm{~s}$ before start of chest compressions, according to guidelines, and with $21 \%$ oxygen. Baseline characteristics (Table 1) and clinical data at asystole and postresuscitation have been discussed in our previous papers $(19,21)$. We found no significant differences between groups 1 and 4, or between groups 6 and 7, regarding gene expression, all data for hippocampus and frontal cortex given in Table 2, or for selected CSF cytokines. This was still valid when we fused groups 1 and 6 and compared group $4(\mathrm{C}: \mathrm{V}, 9: 3)$ to all data in groups $1+6$, and group $7(\mathrm{C}: \mathrm{V}, 15: 2)$ to groups 1 +6 , indicating that groups 4 and 7 were directly comparable. The C:V 3:1 groups (1 and 6) in the two experimental series displayed similar experimental data (except for weight, blood $\mathrm{pH}$, and lactate (Table 3)), indicating that these groups may be directly comparable. We proved similar CSF cytokine concentrations and tissue quantitative real-time PCR (qPCR) in the three $\mathrm{C}: \mathrm{V}$ ratio groups 3:1, 9:3, and 15:2.

S100 concentrations in CSF for group $4(\mathrm{C}: \mathrm{V}, 9: 3)$ were $34.57 \mu \mathrm{g} / \mathrm{l}(17.47-76.91)$ vs. group 1 (27.08 $\mu \mathrm{g} / \mathrm{l}(24.11-62.36))$ and for group 7 (C:V, 15:2), 85.07 $\mu \mathrm{g} / \mathrm{l}(61.37-116.00)$ vs. group $6(\mathrm{C}: \mathrm{V}, 3: 1)(30.18 \mu \mathrm{g} / \mathrm{l}(20.17-82.93)), P=0.69$ and $P=0.18$, respectively. CSF concentrations for IL-6 for group 4 (C:V, 9:3) were $34.57 \mathrm{pg} / \mathrm{ml}(17.47-76.91)$ and group $1(\mathrm{C}: \mathrm{V}, 3: 1), 80.81$ $\mathrm{pg} / \mathrm{ml}(26.82-359.6), P=0.13$. We did not succeed in obtaining CSF from all pigs in groups 4 and 7 ; hence, too few samples were available for analyses and conclusions within the C:V 15:2 group for IL- 6 and TNF- $\alpha$ analyses in all ratio groups.

\section{Resuscitation With 21 vs. $100 \%$ Oxygen}

All pigs were resuscitated with initial ventilation for $30 \mathrm{~s}$ and $\mathrm{C}: \mathrm{V}$ ratio 3:1, according to guidelines. Baseline characteristics (Table 1) and clinical data are given in a previous paper (18) reporting similar ROSC with 21 and 100\% oxygen when resuscitating pigs at asystole. S100 levels in CSF using 100\% oxygen (group 5) were $37.28 \mu \mathrm{g} / \mathrm{l}(21.52-73.38)$ and those using $21 \%$ oxygen (group 1) were $27.08 \mu \mathrm{g} / \mathrm{l}$ (24.11-62.36), $P=0.92$. IL-6 levels in CSF were $30.26 \mathrm{pg} / \mathrm{ml}(24.88-75.98)$ and $80.81 \mathrm{pg} / \mathrm{ml}(26.82-$ 359.6) for groups 5 and 1 , respectively, $P=0.30$. TNF- $a$ levels could not be analyzed because we did not get enough CSF from group 5 (100\% oxygen). Absolute values for genes expressed with the arithmetic formula $2^{-\Delta \mathrm{Ct}}$ and $P$ values are given in Table 2 .

Table 1. Baseline characteristics of experimental groups

\begin{tabular}{|c|c|c|c|c|c|c|c|}
\hline Baseline data & $\begin{array}{c}\mathrm{G} 1 \mathrm{~S} 1(n=16) \\
21 \% \mathrm{O}_{2^{\prime}} 30 \mathrm{~s} \\
\mathrm{C}: \mathrm{V}=3: 1\end{array}$ & $\begin{array}{c}\mathrm{G} 2 \mathrm{~S} 1(n=16) \\
21 \% \mathrm{O}_{2^{\prime}} 60 \mathrm{~s} \\
\mathrm{C}: \mathrm{V}=3: 1\end{array}$ & $\begin{array}{c}\mathrm{G} 3 \mathrm{~S} 1(n=8) \\
21 \% \mathrm{O}_{2^{\prime}} 90 \mathrm{~s} \\
\mathrm{C}: \mathrm{V}=3: 1\end{array}$ & $\begin{array}{c}\mathrm{G} 4 \mathrm{~S} 1(n=16) \\
21 \% \mathrm{O}_{2^{\prime}} 30 \mathrm{~s} \\
\mathrm{C}: \mathrm{V}=9: 3\end{array}$ & $\begin{array}{c}\mathrm{G} 5 \mathrm{~S} 1(n=16) \\
100 \% \mathrm{O}_{2^{\prime}} 30 \mathrm{~s} \\
\mathrm{C}: \mathrm{V}=3: 1\end{array}$ & $\begin{array}{c}\mathrm{G} 6 \mathrm{~S} 2(n=11) \\
21 \% \mathrm{O}_{2^{\prime}}, 30 \mathrm{~s} \\
\mathrm{C}: \mathrm{V}=3: 1\end{array}$ & $\begin{array}{c}\mathrm{G} 7 \mathrm{~S} 2(n=11) \\
21 \% \mathrm{O}_{2^{\prime}} 30 \mathrm{~s} \\
\mathrm{C}: \mathrm{V}=15: 2\end{array}$ \\
\hline Age (h) & $26(6)$ & $27(3)$ & $29(4)$ & $28(3)$ & $30(3)^{*}$ & $30(8)$ & $32(3)$ \\
\hline Weight (g) & $2,270(152)$ & $2,326(105)$ & $2,325(85)$ & $2,402(119)^{*}$ & $2,362(143)$ & $2,531(160)$ & $2,471(186)$ \\
\hline Male/female & $8 / 7$ & $7 / 9$ & $4 / 4$ & $9 / 7$ & $8 / 8$ & $5 / 6$ & $5 / 6$ \\
\hline $\mathrm{HR}(\mathrm{bpm})$ & $151(21)$ & $148(24)$ & $180(24)^{*}$ & $130(18)^{*}$ & $150(28)$ & $167(37)$ & $154(30)$ \\
\hline $\mathrm{pH}$ & $7.38(0.07)$ & $7.40(0.08)$ & $7.31(0.03)^{*}$ & $7.40(0.08)$ & $7.35(0.05)$ & $7.3(0.1)$ & $7.3(0.1)$ \\
\hline $\mathrm{BE}(\mathrm{mmol} / \mathrm{l})$ & $-1.7(3.6)$ & $0.6(4.2)$ & $-2.8(1.6)$ & $0.6(2.8)$ & $-0.1(4.1)$ & $-1.7(2.9)$ & $-2.5(2.9)$ \\
\hline $\mathrm{pCO}_{2}(\mathrm{kPa})$ & $5.0(1.4)$ & $5.5(0.7)$ & $6.3(0.5)$ & $5.7(0.9)$ & $6.5(1.1)$ & $6.5(1.1)$ & $7.0(1.0)$ \\
\hline $\mathrm{SpO}_{2}(\%)$ & $90(6)$ & $93(4)$ & $90(5)$ & $95(6)^{*}$ & $92(5)$ & $88(13)$ & $88(11)$ \\
\hline
\end{tabular}

Values are presented as mean (SD).

$\mathrm{BE}$, base excess; bpm, beats per minute; $\mathrm{C}: \mathrm{V}$, chest compression to ventilation ratio; $\mathrm{G}$, group; $\mathrm{Hb}$, hemoglobin; HR, heart rate; $\mathrm{MAP}$, mean arterial pressure; $\mathrm{S}$, series; SpO , saturation of peripheral oxygen

*P $<0.05$ when the group is compared with group $1\left(21 \% \mathrm{O}_{2}, 30 \mathrm{~s}, \mathrm{C}: \mathrm{V} 3: 1\right)$ (refs. 18-21). 

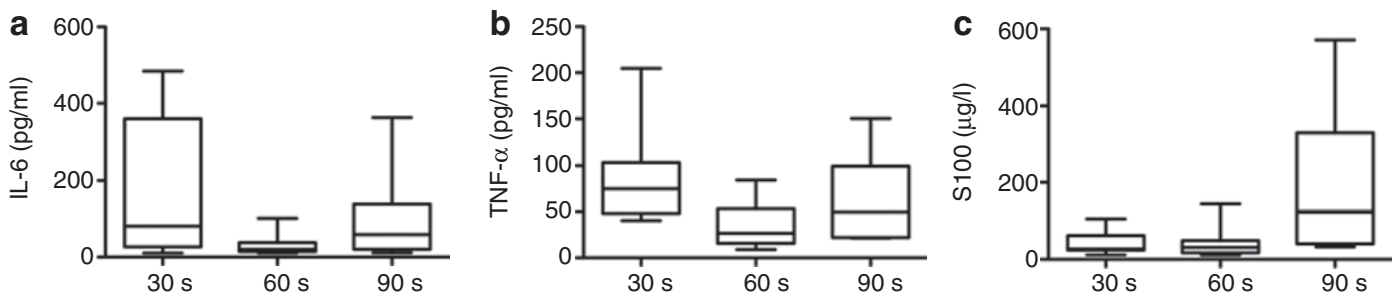

Figure 1. Concentrations in cerebrospinal fluid of $(\mathbf{a}) \mathrm{IL}-6(\mathrm{pg} / \mathrm{ml})(P=0.02$ when comparing groups 2 and $1 ; P=0.35$ when comparing groups 3 and 1); (b) TNF-a (pg/ml) $(P=0.01$ when comparing groups 2 and $1 ; P=0.33$ when comparing groups 3 and 1$)$; and $(\mathbf{c}) \mathrm{S} 100(\mu \mathrm{g} / \mathrm{l})(P=0.88$ when comparing groups 2 and 1; $P=0.01$ when comparing groups 3 and 1). Groups 1-3 represent 30,60, and 90 s, respectively, of initial positive-pressure ventilation before the start of alternating chest compressions and positive-pressure ventilations in a ratio of 3:1 with $21 \%$ oxygen in inspiratory gas. Results are presented as box plots. IL, interleukin; TNF, tumor necrosis factor.

Table 2. Data on gene expression of MMP-2, MMP-9, IL-6, TNF-a, caspase 3, and ICAM-1 in pig brain frontal cortex and hippocampus

\begin{tabular}{|c|c|c|c|}
\hline & & Hippocampus & Frontal cortex \\
\hline Gene symbol & Group no./ventilation, $\mathrm{C}: \mathrm{V}, \mathrm{FiO}_{2}$ & $2^{-\Delta \mathrm{Ct}}$ Median (IQR) & $2^{-\Delta C t}$ Median (IQR) \\
\hline MMP-2 & $1 / 30 s, 3: 1,21 \%$ & $0.92(0.77-1.35)$ & $1.06(0.74-1.66)$ \\
\hline MMP-2 & $3 / 90$ s, 3:1, 21\% & $0.63(0.58-0.90), P=0.18$ & $1.16(0.52-1.94), P=0.94$ \\
\hline MMP-2 & $\mathbf{4} / 30 \mathrm{~s}, \mathbf{9 : 3}, 21 \%$ & $0.97(0.81-1.14), P=0.36$ & $1.16(0.88-1.70), P=0.98$ \\
\hline MMP-9 & $2 / 60 s, 3: 1,21 \%$ & $0.92(0.70-1.25), P=0.58$ & $0.86(0.30-2.35), P=0.71$ \\
\hline MMP-9 & $\mathbf{3} / 90 \mathbf{s}, 3: 1,21 \%$ & $1.92(1.19-2.82), P=0.16$ & $1.66(0.47-3.04), P=0.73$ \\
\hline MMP-9 & $4 / 30 s, 9: 3,21 \%$ & $1.80(0.75-2.78), P=0.43$ & $1.51(0.91-4.42), P=0.62$ \\
\hline MMP-9 & $5 / 30 s, 3: 1,100 \%$ & $1.24(1.02-1.87), P=0.55$ & $0.90(0.26-2.67), P=0.59$ \\
\hline IL-6 & $5 / 30 \mathrm{~s}, 3: 1,100 \%$ & $0.81(0.67-1.01), P=0.56$ & $1.39(0.62-2.32), P=0.84$ \\
\hline TNF-a & $1 / 30 s, 3: 1,21 \%$ & $0.89(0.72-1.50)$ & $1.15(0.69-1.88)$ \\
\hline TNF-a & $2 / 60 s, 3: 1,21 \%$ & $1.05(0.68-1.62), P=0.93$ & $1.19(0.64-2.08), P=0.75$ \\
\hline TNF-a & $\mathbf{3} / 90$ s, $3: 1,21 \%$ & $0.91(0.67-1.98), P=0.94$ & $1.60(0.17-3.00), P=0.57$ \\
\hline TNF-a & $4 / 30 s, 9: 3,21 \%$ & $0.90(0.72-1.39), P=0.85$ & $1.29(0.92-1.86), P=0.63$ \\
\hline TNF-a & $5 / 30 \mathrm{~s}, 3: 1,100 \%$ & $1.10(0.65-1.68), P=0.89$ & $1.49(0.88-2.55), P=0.69$ \\
\hline Caspase 3 & $1 / 30 s, 3: 1,21 \%$ & $1.04(0.88-1.10)$ & $0.92(0.72-1.29)$ \\
\hline Caspase 3 & $2 / 60 s, 3: 1,21 \%$ & $0.82(0.78-0.95), P=0.82$ & $1.15(0.94-1.85), P=0.17$ \\
\hline Caspase 3 & $3 / 90$ s, 3:1, $21 \%$ & $0.89(0.83-1.28), P=0.32$ & $1.11(0.72-1.22), P=0.92$ \\
\hline ICAM-1 & $5 / 30 \mathrm{~s}, 3: 1,100 \%$ & $1.42(1.05-2.21), P=0.39$ & $1.28(0.72-1.65), P=0.75$ \\
\hline
\end{tabular}

Data are presented as 2-ACt (median (IQR)) for groups 1-5. P values for comparisons with group 1. Bold letters explain variations from group 1.

$\mathrm{C}: \mathrm{V}$, chest compression to ventilation ratio; $\mathrm{FiO}_{2}$, fraction of inspired oxygen; ICAM-1, intracellular adhesion molecule 1; IL, interleukin; IQR, interquartile range; MMP, matrix metalloproteinase; TNF, tumor necrosis factor.

\section{DISCUSSION}

There is a paucity of data to support resuscitation recommendations in the newly born, both for optimal ventilation time before cardiac compressions start and for which $\mathrm{C}: \mathrm{V}$ ratio should be used. Guidelines are generally based on expert consensus and data from animal, pediatric, and adult models. Therefore, we raised the question if longer initial ventilation periods or longer series of compressions in a row, i.e., 
Table 3. Characteristics at baseline in reference groups

\begin{tabular}{lccc}
\hline & Group 1, series 1, & Group 6, series 2, & \\
& $n=16$ & $n=11$ & $P$ value \\
\hline Age $(\mathrm{h})$ & $26(6)$ & $30(8)$ & 0.16 \\
Weight $(\mathrm{g})$ & $2,270(152)$ & $2,531(160)$ & $<0.001^{*}$ \\
Male/female & $8 / 7$ & $6 / 5$ & 1.00 \\
HR (bpm) & $151(21)$ & $167(37)$ & 0.17 \\
MAP $(\mathrm{mm} \mathrm{Hg})$ & $60(14)$ & $60(17)$ & 1.00 \\
pH & $7.38(0.07)$ & $7.30(0.1)$ & $0.02^{*}$ \\
BE $(\mathrm{mmol} / \mathrm{l})$ & $-1.7(3.6)$ & $-1.7(2.9)$ & 1.00 \\
pCO2 $(\mathrm{kPa})$ & $5.5(1.4)$ & $6.5(1.1)$ & 0.06 \\
SpO2 $(\%)$ & $90(6)$ & $88(13)$ & 0.60 \\
Glucose $(\mathrm{mmol} / \mathrm{l})$ & $7.8(1.9)$ & $7.9(1.9)$ & 0.90 \\
Lactate $(\mathrm{mmol} / \mathrm{l})$ & $2.9(0.9)$ & $1.3(0.5)$ & $<0.001^{*}$ \\
Arterial Hb (g/dl) & $7.1(0.9)$ & $7.1(0.8)$ & 1.00 \\
\hline Comparsof & &
\end{tabular}

Comparison of the two reference groups, 1 and 6 (pigs ventilated 30 s, 21\% oxygen before chest compressions and ventilations at a C:V ratio of 3:1 (refs. 19,21)). Values are presented as mean (SD).

$\mathrm{BE}$, base excess; bpm, beats per minute; $\mathrm{C}: \mathrm{V}$, chest compression to ventilation ratio; $\mathrm{Hb}$ hemoglobin; HR, heart rate; MAP, mean arterial pressure; $\mathrm{SpO}_{2}$, saturation of peripheral oxygen.

${ }^{*} P<0.05$ between reference groups.

Table 4. The newborn pig groups in two experimental series on resuscitation from asystole

\begin{tabular}{lcccc}
\hline $\begin{array}{l}\text { Group no. } \\
(n, \text { pigs) }\end{array}$ & $\begin{array}{c}\text { Ventilation } \\
\text { time before } \\
\text { compressions }\end{array}$ & $\begin{array}{c}\text { Chest } \\
\text { compression- } \\
\text { to-ventilation } \\
\text { ratio (C:V) }\end{array}$ & $\begin{array}{c}\text { Oxygen } \\
\text { concentration }\end{array}$ & $\begin{array}{c}\text { Experimental } \\
\text { series number }\end{array}$ \\
\hline $1(n=16)$ & $30 \mathrm{~s}$ & $3: 1$ & $21 \%$ & 1 \\
$2(n=16)$ & $60 \mathrm{~s}$ & $3: 1$ & $21 \%$ & 1 \\
$3(n=8)$ & $90 \mathrm{~s}$ & $3: 1$ & $21 \%$ & 1 \\
$4(n=16)$ & $30 \mathrm{~s}$ & $9: 3$ & $21 \%$ & 1 \\
$5(n=16)$ & $30 \mathrm{~s}$ & $3: 1$ & $100 \%$ & 1 \\
$6(n=11)$ & $30 \mathrm{~s}$ & $3: 1$ & $21 \%$ & 2 \\
$7(n=11)$ & $30 \mathrm{~s}$ & $15: 2$ & $21 \%$ & 2 \\
\hline
\end{tabular}

alternative $\mathrm{C}: \mathrm{V}$ ratios, could possibly limit the extent of brain inflammation in resuscitation of severely asphyxiated newborn pigs. We were curious to find if room air is better than $100 \%$ oxygen in resuscitation of these pigs with extreme acidosis at asystole. We found that a $30 \mathrm{~s}$ longer ventilation period before onset of compressions should be considered (20). All variations in C:V ratios such as 3:1, 9:3, and 15:2 gave similar ROSC $(18,19)$. Here, we report that markers of brain inflammation are indifferent between ratio groups. This is an important observation and supports that as long as compressions and ventilations are provided hands-on and effectively, the specific C:V ratio applied is not so decisive. It may be best to choose the easiest to teach and perform. For example, in the one-rescuer situation, it may be easier to perform the 9:3 than the 3:1 approach.

The inflammatory protein $\mathrm{S} 100$ is identified as a good prognostic factor of neurological outcome after cardiac arrest and an early predictor of brain damage (11). S100 is a sensitive parameter for brain damage, and high levels of S100 in CSF and other biological fluids are associated with fatal outcome (12). Anticipating that a high vs. low S100 concentration is indicative of a more severe brain damage and injury, our results suggest that $90 \mathrm{~s}$ of only ventilation is too long without chest compressions to push blood out so that oxygenated blood can circulate to organs (including the brain) and peripheral tissue. The $\mathrm{S} 100$ data are in accordance with experimental and ROSC data (20) but are not supported by CSF levels of IL- 6 and TNF- $\alpha$, which are similar in the 30 and 90s groups, reflecting different inflammatory response mechanisms. This indicates that the optimal ventilation time before compression starts is somewhere between 60 and 90 s.

The choice of brain inflammation markers is somewhat limited but includes cytokines that rise within few hours after an inflammatory event (TNF- $\alpha$ and IL-6) (7-10); S100 $(11,12)$, indicative of poor neurological outcome; ICAM-1 (15-17); the apoptosis pathway gene (caspase 3) (14); and MMPs $(13,14)$, known to rise in pigs after hypoxia and reoxygenation. In group 3 (90 s), the CSF markers S100, IL-6, and TNF- $\alpha$ were elevated as compared with the reference group, and in the hippocampus tissue, MMP-9 and ICAM-1 genes appeared significantly differently expressed. We have no obvious explanation why a ventilation period of $60 \mathrm{~s}$ (group 2) produces lower CSF concentrations of IL- 6 and TNF- $\alpha$ and less expression of hippocampus MMP-2 and ICAM-1 genes as compared with the reference group. One suggestion may be that the 30s longer period with chest compressions (groups have similar ROSC) produces 40-50 more chest compressions, inducing signs of inflammation in the central nervous system. We speculate that the chest trauma produces circulating proinflammatory mediators that can be measured in CSF and also measured indirectly by changed gene expressions of inflammatory genes in the brain tissue as is also reported in a mouse model of blunt trauma (22). The longer ventilation interval reduces the risk of extensive trauma with rib fractures and pulmonary contusion that we observed in some of our newborn pigs. Furthermore, in the delivery room, this delayed onset of compressions may give the medical providers time to focus on improving ventilation before initiating cardiac compressions.

Our group has previously reported detrimental brain effects caused by hyperoxia $(1,14,23-25)$. Those pigs were bradycardic and hypotensive but not as extremely sick as the asphyxiated pigs reported here with base excess $<-30 \mathrm{mmol} / \mathrm{l}, \mathrm{pH} 6.7$, and high $\mathrm{PaCO}_{2}$ (18) at asystole. We prove that room air is as good as pure oxygen, with respect to brain injury, even in these pigs resuscitated from asystole. The International Liaison Committee on Resuscitation recommendations of 2010 state that infants born at term should be resuscitated with air initially rather than $100 \%$ oxygen and administration of supplementary oxygen should be guided by oximetry (5). According to our data, air should be used also in these severely asphyxiated pigs.

MMPs seem to regulate brain damage and repair after severe hypoxia-reoxygenation $(26,27)$ and that may be true in these pigs too because the MMP-2 gene is less expressed 
Table 5. Primers for quantitative real-time PCR

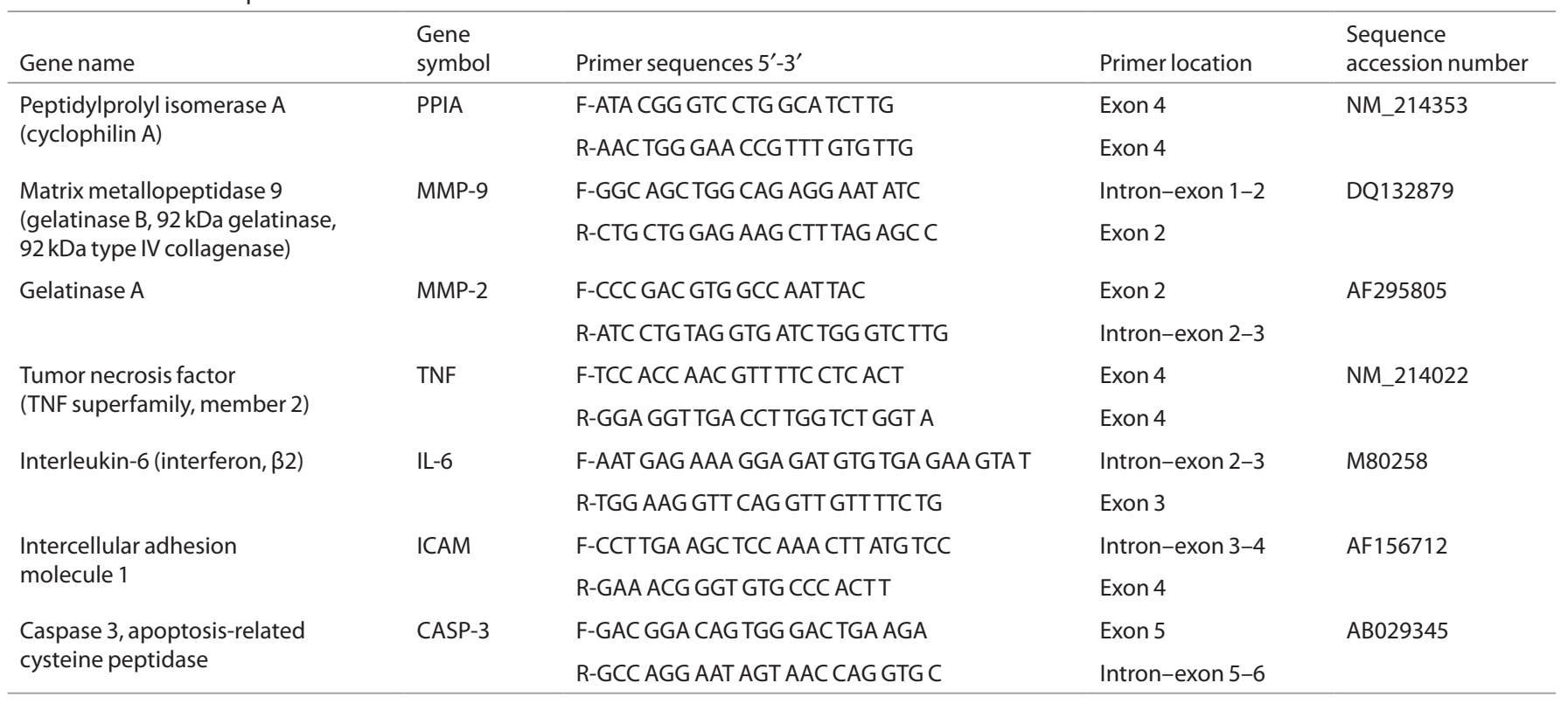

F, forward primer; IL, interleukin; $\mathrm{QPCR}$, quantitative real-time $P C R ; R$, reverse primer.

in the hippocampus in the 60s compared with the 30 s group. The relevance of studying MMPs is their regulation of tissue inflammation in response to oxidative stress; MMP-9 induces neuronal death, whereas MMP-2 plays a role in neuronal damage (14). Bednarek et al. (28) also found that MMP-9 might be a potential marker of neonatal encephalopathy in mouse brains. The adhesion molecule ICAM-1 is important in the transmigration of immune cells through the blood-CSF barrier under inflammatory conditions such as asphyxia-induced brain injury (29) and also in promoting adhesion and homing of leukocytes into the brain $(15,16)$. Of note, frontal cortex ICAM-1 gene expression varied with the initial ventilation time, being less expressed in the 60 s group. IL- 6 and TNF- $\alpha$ are important mediators of the acute-phase response and are also downregulated in brain protection induced by hypothermia (30). We found lower CSF concentrations of IL- 6 and TNF- $\alpha$ in the 60s group but no difference in tissue TNF- $\alpha$ gene expression at $4 \mathrm{~h}$ after ROSC. Furthermore, severe neonatal hypoxia correlates with chorioamnionitis and raised concentrations of IL-6 (7), which is quite in line with the findings here suggesting that high levels of cytokines contribute and reflect the severity of hypoxic failure. IL-6 is an early and important mediator of inflammatory responses. Excessive and prolonged postinjury elevations are associated with increased morbidity (8). It has been suggested that initial IL-6 release in multiple trauma patients is related to the extent of tissue damage (9). The higher TNF- $\alpha$ concentration in the 30 s group, indicating more extensive brain injury, is interesting because increased TNF- $\alpha$ in the amnion and fetal blood do correlate with an increased risk of developing periventricular leukomalacia and cerebral palsy and can be reduced after antioxidant therapy (31).
Our findings apply to term infants because these newborn pigs have several similarities to human newborns with regard to anatomy, size, immunology, and susceptibility to hypoxia. The level of development of the neonatal pig's brain is comparable with that of a term human newborn (10). A potential weakness of our study design may be that the experiments were performed on animals that had undergone the transition from intra to extrauterine life. This occurs during the first few hours of life and these pigs were $12 \mathrm{~h}$ old or more. Baseline characteristics were slightly different between groups as illustrated in Tables 1 and 3, and we cannot exclude that this may have an impact on the brain inflammatory response. When we started resuscitation, our animals had an HR of zero as evaluated by electrocardiogram, invasive blood pressure, and auscultation, as opposed to newborn babies with bradycardia needing resuscitation. The myocardial function of these pigs can be assumed to have been severely depressed for several hours. Our animals were considerably sicker than most asphyxiated newborns seen in the clinic, and it is of major importance that resuscitation with only $21 \%$ oxygen was good enough to resuscitate almost all pigs from asystole to spontaneous circulation.

A weakness in this report, regarding CSF data, may be that the seven pig groups were randomized and run in two different experimental series (Table 4); one during autumn months and the other in springtime analyzing the C:V ratio $15: 2$ vs. 3:1. The control groups, 30s ventilation, and $\mathrm{C}: \mathrm{V}$ ratio of $3: 1$ in $21 \%$ oxygen were identically designed, but a comparison of baseline data showed some differences, i.e., weight, blood $\mathrm{pH}$, and lactate (Table 3), between the two groups and we cannot rule out an effect of this. C:V ratios of 9:3 or 15:2 appeared no better or worse than the currently recommended ratio of $3: 1$, at least according to brain inflammation markers presented here and time to ROSC as reported previously $(19,21)$. 
A strength in this study of 94 newborn pigs would have been inclusion of sham control pigs, subjected to the same procedures and observation time but no hypoxia, hyperoxia, or cardiac arrest. We did not include sham animals in this study in which the intention was to compare different resuscitation variations represented by seven groups of 94 animals described in Table 1. Previous experimental series in our lab have clearly demonstrated brain inflammatory responses after asphyxia followed by reoxygenation and resuscitation $(13,26)$, and we argue that this also applies when pigs are more severely asphyxiated.

A search of the literature led us to the time points and parameters selected for this protocol. Four hours postresuscitation may not be the optimal time to find changes in CSF or in brain tissue of inflammatory mediator genes. Except for MMP-2 and ICAM-1 gene expression in the hippocampus and frontal cortex, no differences could be detected between groups. We realize that time-response experiments should ideally have been performed for each parameter. This would have necessitated many more animals in order to find and carry through experiments at the different defined optimal time points, which is not in line with recommendations by the Norwegian Council for Animal Research.

The International Liaison Committee on Resuscitation, the American Heart Association, and the American Academy of Pediatrics have recently established their new guidelines for newborn resuscitation, but a number of unanswered questions remain (5). With focus on inflammatory responses in the central nervous system, we conclude that resuscitation of newborns should include a ventilation period longer than 30 $s$ before starting chest compressions. The $\mathrm{C}: \mathrm{V}$ ratios of $9: 3$ and 15:2 are, with respect to brain inflammation, as good as the recommended 3:1. Because we observed no difference in the signs of inflammation, it may be safe to choose "the easiest to perform in practice" strategy. Quality-of-performance studies, rescuer fatigue studies, and studies in infants with primary hypoxic, hypercapnic cardiac arrest should be undertaken to explore and evaluate these issues.

\section{METHODS}

\section{The Pig Model}

The newborn pig model matches the human newborn in size and weight, anatomy and physiology (32), brain growth and myelinization (33), maturation (34), and distribution of gray/white matter (35); these parameters are all comparable with those in human neonates. The experimental protocol was approved by the Norwegian Council for Animal Research. The animals were cared for and handled in accordance with the European Guidelines for Use of Experimental Animals by certified Federation of European Laboratory Animal Science Associations category $\mathrm{C}$ researchers. Exclusion criteria were arterial $\mathrm{Hb}<6 \mathrm{~g} / \mathrm{dl}$ or poor general condition (e.g., hypotension, bradycardia).

\section{Pig Preparation}

All pigs were of similar type as in previous papers (18-20). Two experimental series of 72 and 22 newborn Noroc pigs (Table 4) (14-34h of age and $2.0-2.7 \mathrm{~kg}$ ) were anesthetized with Sevofluran before being given pentobarbital, midazolam, and fentanyl; they were then tracheotomized and mechanically ventilated. The left external jugular vein and the right common carotid artery were cannulated for continuous infusions of fentanyl and midazolam, and continuous blood pressure and
HR monitoring, respectively. Pigs were stabilized on the ventilator for $1 \mathrm{~h}$ before asphyxiation with ventilation settings: inspiratory time 0.4 $\mathrm{s}$, peak inspiratory pressure 25 , positive end-expiratory pressure $5 \mathrm{~cm}$ $\mathrm{H}_{2} \mathrm{O}$, and a rate adjusted to achieve a $\mathrm{pCO}_{2}$ between 4.5 and $6 \mathrm{kPa}$ with $21 \%$ oxygen (Babylog $8000+$, Drägerwerk, Lübeck, Germany). The pigs were then introduced to progressive asphyxia by adding $\mathrm{CO}_{2}$ to achieve a $\mathrm{pCO}_{2}>7.0 \mathrm{kPa}$, oxygen reduced to $8 \%$, and the ventilator rate reduced by 10 breaths per min every $10 \mathrm{~min}$ until asystole, which was defined as a mean arterial pressure of $0 \mathrm{~mm} \mathrm{Hg}$ and a flat electrocardiogram. Cardiac auscultation was performed to assess the state of the animal. Baseline data (Table 1) and the experimental protocol were similar in the two series, and the second series was run 3 mo after the first. ROSC was defined as an HR of $\geq 100$ beats per min, eventually after adrenaline $(0.02 \mathrm{mg} / \mathrm{kg})$ was administered first after $1 \mathrm{~min}$ and then every $3 \mathrm{~min}$ until an HR $\geq 60$ beats per min was achieved. Each chest compression was aimed to generate a mean arterial pressure $\geq 20 \mathrm{~mm} \mathrm{Hg}$. The ventilator was used instead of a resuscitation bag to obtain standardized ventilations in terms of pressure and duration of individual ventilations. Pauses in cardiac compressions were made in order for effective ventilations to occur after each compression cycle.

\section{Randomization}

Animals were stratified with respect to gender and randomized by pulling folded cards, and in experimental series 1 they were assigned to one of five groups after cardiac arrest (groups 1-4 with $21 \%$ oxygen in inspired air): the reference group (group 1), chest $\mathrm{C}: \mathrm{V}$ ratio $3: 1$ after 30 $\mathrm{s}$ of ventilation; group 2, C:V ratio 3:1 after $60 \mathrm{~s}$ of ventilation; group 3, $\mathrm{C}: \mathrm{V}$ ratio 3:1 after $90 \mathrm{~s}$ of ventilation; group 4, C:V ratio 9:3 after $30 \mathrm{~s}$ of ventilation; or group 5, 21\% oxygen and 100\% oxygen applying $30 \mathrm{~s}$ of initial ventilation before compression and ventilation at a ratio of $3: 1$. In pig series 2, pigs were randomized to using $21 \%$ oxygen, $\mathrm{C}: \mathrm{V}$ ratio 3:1, after $30 \mathrm{~s}$ of ventilation (group 6) or C:V ratio 15:2 after $30 \mathrm{~s}$ of ventilation (group 7). An overview of the different randomized groups is presented in Table 4. Monitoring and data on clinical parameters for these pigs are described in previous papers (18-21).

\section{Sampling}

Four hours after ROSC, $1-2 \mathrm{ml}$ of CSF were harvested through a lumbal puncture and immediately frozen in liquid nitrogen and stored at $-80^{\circ} \mathrm{C}$. The animal was then killed and the brain was immediately removed. Brain tissue from the hippocampus and frontal cortex was placed in polypropylene tubes, immediately frozen in liquid nitrogen, and then stored at $-80^{\circ} \mathrm{C}$.

\section{Cytokine Analysis of CSF}

Spike and recovery and linearity experiments were performed on CSF samples on porcine Quantikine IL-6 (P6000) immunoassay from R\&D Systems (Minneapolis, MN) using the Spike and Recovery Immunoassay Sample Validation Protocol from R\&D Systems. The validation experiment showed good values. CSF samples were analyzed in singlets on Quantikine, porcine IL-6, and TNF- $a$ (PTA00) (R\&D systems) following the manufacturer's instructions for cell culture supernatant samples. Samples were measured spectrophotometrically at $450 \mathrm{~nm}$ with wavelength correction set to $540 \mathrm{~nm}$ using SkanIt Software version 2.4.3 for Thermo Electron Varioskan reader (Thermo Fisher Scientific, Waltham, MA). The recommended four-parameter logistic curve-fit method was used for automatic calculation of IL- 6 and TNF- $\alpha$ results.

\section{S100 Analysis of CSF}

CSF samples were diluted 14-200 times in physiological saline and analyzed in duplicates on CanAg S100 enzyme immunometric assay (Fujirebio Diagnostics AB, Gothenburg, Sweden) following the manufacturer's instructions for human serum samples. Samples were measured spectrophotometrically at $620 \mathrm{~nm}$ using Thermo Electron Varioskan reader and SkanIt Software version 2.4.3. The recommended cubic spline curve-fit method was used for automatic calculation of S100 results.

\section{Reverse Transcription-qPCR}

In a real-time PCR assay, a positive reaction is detected by accumulation of a fluorescent signal. The Ct (cycle threshold) is defined as the number of cycles required for the fluorescent signal to cross the threshold. 
Tissue samples of $30 \mathrm{mg}$ from the frontal cortex and hippocampus were homogenized in $1 \mathrm{ml}$ lysis buffer using OmniTip (Omni International, Kennesaw, GA). Total RNA from the supernatant was extracted using Ezna Total RNA purification kit II (Omega Bio-Tek, Norcross, GA) with DNase (Omega Bio-Ttek) treatment. The quantity and quality (A260/280 and A260/230) of total RNA were assessed using the NanoDrop ND-1000 Spectrophotometer (NanoDrop Technologies, Wilmington, DE). Total RNA of $2 \mu \mathrm{g}$ was reverse transcribed into complementary DNA using the High Capacity cDNA Reverse Transcription Kit (Part Number 4368814; Applied Biosystems, Carlsbad, CA) with a reaction volume of $40 \mu \mathrm{l}$. qPCR was performed with $50 \mathrm{ng}$ complementary DNA, $400 \mathrm{nmol} / \mathrm{l}$ of each primer (Table 5), and SYBR Green PCR Master mix in a reaction volume of $25 \mu$ l. The reaction mix was manually pipetted in duplicate on an ABgene 96-well PCR plate (Thermo Scientific, Asheville, NC), and the plate was run on the ABI Prism 7300 Real-time PCR System (Applied Biosystems) with universal instrument settings. Initial data analyses were performed using ABI Prism SDS1.3.1 software (Applied Biosystems). The melting curves obtained showed single peaks, indicating that single amplicons were generated by qPCR. All amplification efficiencies were above $90 \%$. All no-template controls were acceptable. Peptidylprolyl isomerise A was used as a reference gene for normalization. Relative expression was determined by the comparative Ct-method of relative quantification, calculated with the arithmetic formula $2^{-\Delta \mathrm{Ct}}$, where $\Delta \mathrm{Ct}$ is the normalized signal level in a sample $(\Delta \mathrm{Ct}$ $=\mathrm{Ct}$ of target gene $-\mathrm{Ct}$ of endogenous control gene) (36).

\section{Sample Size and Data Analysis}

Power analysis for the first experimental series was performed based on data from a pilot study to detect a difference of $50 \mathrm{~s}$ (determined as a "clinically significant" difference) in time to ROSC between treatment arms with a power of $80 \%$ and a type I error rate of $5 \%$. Sixteen pigs were randomized to each group in the first experimental series. Group 3 (90 s) included only eight animals because times to ROSC in this group halfway through the study were already significantly longer (all pigs) as compared with those in group 1 (30 s) and group 2 (60 s). Power analyses for the second series (C:V ratio $15: 2$ vs. 3:1, groups 6 and 7 ) were based on ROSC data from the first series as described in a previous paper (20).

Statistical analysis was performed using SPSS 15.0 for Windows (SPSS, Chicago, IL). Two independent sample $t$-tests were used for symmetrical variables for comparison between groups. Otherwise, the Mann-Whitney test was used. Descriptive statistics are presented as median and interquartile range. $P$ values $<0.05$ were considered statistically significant. $P$ values are not Bonferroni-corrected.

\section{ACKNOWLEDGMENTS}

Geir Aamodt and Bettina Kulle Andreassen are specifically thanked for important and valuable statistical help and valuable suggestions, and Grete Dyrhaug and Monica Atneosen-Åsegg for optimizing the qPCR results.

\section{STATEMENT OF FINANCIAL SUPPORT}

The South-Eastern Norway Regional Health Authority, the Laerdal Foundation of Acute Medicine, and Akershus University Hospital contributed economically to the study.

\section{REFERENCES}

1. Dalen ML, Alme TN, Bjørås M, Munkeby BH, Rootwelt T, Saugstad OD. Reduced expression of DNA glycosylases in post-hypoxic newborn pigs undergoing therapeutic hypothermia. Brain Res 2010;1363:198-205.

2. Perlman JM. Intervention strategies for neonatal hypoxic-ischemic cerebral injury. Clin Ther 2006;28:1353-65.

3. Stevenson DK. Fetal and Neonatal Brain Injury, 4th edn. Cambridge, UK: Cambridge University Press, 2009.

4. Richmond S, Wyllie J. European Resuscitation Council Guidelines for Resuscitation 2010 Section 7. Resuscitation of babies at birth. Resuscitation 2010;81:1389-99.

5. Perlman JM, Wyllie J, Kattwinkel J, et al. Part 11: Neonatal resuscitation: 2010 International Consensus on Cardiopulmonary Resuscitation and Emergency Cardiovascular Care Science With Treatment Recommendations. Circulation 2010;122:16 Suppl 2:S516-38.
6. Perlman JM, Risser R. Cardiopulmonary resuscitation in the delivery room. Associated clinical events. Arch Pediatr Adolesc Med 1995;149:20-5.

7. Woldesenbet M, Rosenfeld CR, Ramilo O, Johnson-Welch S, Perlman JM. Severe neonatal hypoxic respiratory failure correlates with histological chorioamnionitis and raised concentrations of interleukin 6 (IL6), IL8 and C-reactive protein. Arch Dis Child Fetal Neonatal Ed 2008;93:F413-7.

8. Gebhard F, Pfetsch H, Steinbach G, Strecker W, Kinzl L, Brückner UB. Is interleukin 6 an early marker of injury severity following major trauma in humans? Arch Surg 2000;135:291-5.

9. Strecker W, Gebhard F, Perl M, et al. Biochemical characterization of individual injury pattern and injury severity. Injury 2003;34:879-87.

10. Huang CC, Yonetani M, Lajevardi N, Delivoria-Papadopoulos M, Wilson DF, Pastuszko A. Comparison of postasphyxial resuscitation with $100 \%$ and $21 \%$ oxygen on cortical oxygen pressure and striatal dopamine metabolism in newborn piglets. J Neurochem 1995;64:292-8.

11. Bennet L, Booth L, Gunn AJ. Potential biomarkers for hypoxic-ischemic encephalopathy. Semin Fetal Neonatal Med 2010;15:253-60.

12. Vos PE, Jacobs B, Andriessen TM, et al. GFAP and S100B are biomarkers of traumatic brain injury: an observational cohort study. Neurology 2010;75:1786-93.

13. Munkeby BH, Børke WB, Bjørnland $\mathrm{K}$, et al. Resuscitation of hypoxic piglets with $100 \% \mathrm{O} 2$ increases pulmonary metalloproteinases and IL-8. Pediatr Res 2005;58:542-8.

14. Solberg R, Løberg EM, Andresen JH, et al. Resuscitation of newborn piglets. short-term influence of $\mathrm{FiO} 2$ on matrix metalloproteinases, caspase-3 and BDNF. PLoS ONE 2010;5:e14261.

15. Meybohm P, Gruenewald M, Zacharowski KD, et al. Mild hypothermia alone or in combination with anesthetic post-conditioning reduces expression of inflammatory cytokines in the cerebral cortex of pigs after cardiopulmonary resuscitation. Crit Care 2010;14:R21.

16. Librizzi L, Regondi MC, Pastori C, Frigerio S, Frassoni C, de Curtis M. Expression of adhesion factors induced by epileptiform activity in the endothelium of the isolated guinea pig brain in vitro. Epilepsia 2007; 48:743-51.

17. Zhao H, Li CS, Gong P, et al. Molecular mechanisms of therapeutic hypothermia on neurological function in a swine model of cardiopulmonary resuscitation. Resuscitation 2012;83:913-20.

18. Solevåg AL, Dannevig I, Nakstad B, Saugstad OD. Resuscitation of severely asphyctic newborn pigs with cardiac arrest by using $21 \%$ or $100 \%$ oxygen. Neonatology 2010;98:64-72.

19. Solevåg AL, Dannevig I, Wyckoff M, Saugstad OD, Nakstad B. Extended series of cardiac compressions during CPR in a swine model of perinatal asphyxia. Resuscitation 2010;81:1571-6.

20. Dannevig I, Solevåg AL, Wyckoff $\mathrm{M}$, Saugstad OD, Nakstad B. Delayed onset of cardiac compressions in cardiopulmonary resuscitation of newborn pigs with asphyctic cardiac arrest. Neonatology 2011;99:153-62.

21. Solevåg AL, Dannevig I, Wyckoff M, Saugstad OD, Nakstad B. Return of spontaneous circulation with a compression:ventilation ratio of 15:2 versus 3:1 in newborn pigs with cardiac arrest due to asphyxia. Arch Dis Child Fetal Neonatal Ed 2011;96:F417-21.

22. Knöferl MW, Liener UC, Seitz DH, et al. Cardiopulmonary, histological, and inflammatory alterations after lung contusion in a novel mouse model of blunt chest trauma. Shock 2003;19:519-25.

23. Dalen ML, Alme TN, Munkeby BH, et al. Early protective effect of hypothermia in newborn pigs after hyperoxic, but not after normoxic, reoxygenation. J Perinat Med 2010;38:545-56.

24. Dalen ML, Liu X, Elstad M, et al. Resuscitation with $100 \%$ oxygen increases injury and counteracts the neuroprotective effect of therapeutic hypothermia in the neonatal rat. Pediatr Res 2012;71:247-52.

25. de Lange C, Brabrand K, Emblem KE, et al. Cerebral perfusion in perinatal hypoxia and resuscitation assessed by transcranial contrast-enhanced ultrasound and 3 T MRI in newborn pigs. Invest Radiol 2011;46:686-96.

26. Munkeby BH, Børke WB, Bjørnland K, et al. Resuscitation with $100 \%$ O2 increases cerebral injury in hypoxemic piglets. Pediatr Res 2004;56:783-90.

27. Sunagawa S, Ichiyama T, Honda R, Fukunaga S, Maeba S, Furukawa S. Matrix metalloproteinase- 9 and tissue inhibitor of metalloproteinase-1 in perinatal asphyxia. Brain Dev 2009;31:588-93. 


\section{Articles | Danneviget al.}

28. Bednarek N, Svedin P, Garnotel R, et al. Increased MMP-9 and TIMP-1 in mouse neonatal brain and plasma and in human neonatal plasma after hypoxia-ischemia: a potential marker of neonatal encephalopathy. Pediatr Res 2012;71:63-70.

29. Wewer C, Seibt A, Wolburg H, et al. Transcellular migration of neutrophil granulocytes through the blood-cerebrospinal fluid barrier after infection with Streptococcus suis. J Neuroinflammation 2011;8:51.

30. Zhao H, Li CS, Gong P, et al. Molecular mechanisms of therapeutic hypothermia on neurological function in a swine model of cardiopulmonary resuscitation. Resuscitation 2012;83:913-20.

31. Rezaie P, Dean A. Periventricular leukomalacia, inflammation and white matter lesions within the developing nervous system. Neuropathology 2002;22:106-32.
32. Hannon JP, Bossone CA, Wade CE. Normal physiological values for conscious pigs used in biomedical research. Lab Anim Sci 1990;40: 293-8.

33. Pond WG, Boleman SL, Fiorotto ML, et al. Perinatal ontogeny of brain growth in the domestic pig. Proc Soc Exp Biol Med 2000;223:102-8.

34. Laptook A, Stonestreet BS, Oh W. The effects of different rates of plasmanate infusions upon brain blood flow after asphyxia and hypotension in newborn piglets. J Pediatr 1982;100:791-6.

35. Thoresen M, Haaland K, Løberg EM, et al. A piglet survival model of posthypoxic encephalopathy. Pediatr Res 1996;40:738-48.

36. Livak KJ, Schmittgen TD. Analysis of relative gene expression data using real-time quantitative PCR and the 2(-Delta Delta C(T)) Method. Methods 2001;25:402-8. 